\title{
A DOENÇA COMO METÁFORA RACIAL: A PANDEMIA DE CORONAVÍRUS À LUZ DA TEORIA RACIAL CRÍTICA
}

ILLNESS AS A RACIAL METAPHOR: THE CORONAVIRUS PANDEMIC IN THE LIGHT OF CRITICAL RACE THEORY

\section{RESUMO}

Nosso paper irá se debruçar sobre um problema específico: a maneira como, no imaginário jurídico e político de nossa civilização, grupos raciais subalternizados (negros, indígenas, asiáticos etc.) são associados a determinadas doenças. O rabalho se desenvolverá em três etapas: em um primeiro momento, discutiremos, de forma ampla, as reverberações do racismo estrutural sobre a pandemia de COVID-19; em seguida, faremos uma breve apresentação da Teoria Racial Crítica (exercício que se revela necessário, considerando que se trata de uma corrente jusfilosófica ainda pouco debatida, no Brasil); por fim, recorreremos à CRT para refletir sobre como, em um imaginário social racista, populações não-brancas tendem a ser representadas como vetores de doenças. Considerando as tentativas, de governos como o britânico, o estadunidense e o brasileiro, de imputar à China a difusão do COVID-19, recorreremos à Teoria Racial Crítica Asiática - AsianCrit -, uma das inúmeras vertentes da CRT, como ponto de partida para debater a racialização da doença.

Palavras-chave: Teoria Racial Crítica; pandemia de coronavírus; apartheid sanitário.
Philippe Oliveira de Almeida*

\section{ABSTRACT}

Our paper will focus on a specific problem: the way in which, in the legal and political imaginary of our civilization, subalternized racial groups (blacks, indigenous peoples, Asians, etc.) are associated with certain diseases. The work will be developed in three stages: at first, we will discuss, in a broad way, the reverberations of structural racism on the COVID-19 pandemic; then, we will make a brief presentation of the Critical Racial Theory (an exercise that proves to be necessary, considering that it is a philosophical current that is still little debated in Brazil); finally, we will turn to CRT to reflect on how, in a racist social imaginary, non-white populations tend to be represented as disease vectors. Considering the attempts, by governments such as the British, the US and the Brazilian, to impute the dissemination of COVID-19 to China, we will use the Asian Critical Racial Theory - AsianCrit -, one of the numerous aspects of CRT, as a starting point to debate the racialization of the disease.

Keywords: Critical Race Theory; coronavirus pandemic; sanitary apartheid.

* Doutor e Mestre em Direito pela Universidade Federal de Minas Gerais.

Pós-Doutor em Direito pelo Centro de Ciências Jurídicas da Universidade Federal de Santa Catarina.

Professor Adjunto da Faculdade Nacional de Direito da Universidade Federal do Rio de Janeiro.

philippeoalmeida@gmail.com 


\title{
SUMÁRIO
}

\author{
1 INTRODUÇÃO: O NÃO-BRANCO COMO “AGENTE INFECCIOSO"; 2 O CORPO COMO CAMPO DE \\ ENFRENTAMENTOS POLÍTICOS: APARTHEID SANITÁRIO E COVID-19; 3 UMA BREVE HISTÓRIA DA \\ TEORIA RACIAL CRÍTICA; 4 A TEORIA RACIAL CRÍTICA ASIÁTICA E O “VÍRUS CHINÊS”; 5 CONCLUSÃO: \\ UM PASSO ALÉM DE SONTAG; REFERÊNCIAS.
}

\section{- INTRODUÇÃO: O NÃO-BRANCO COMO “AGENTE INFECCIOSO”}

A pandemia de COVID-19 desencadeou um sem-número de dilemas morais, jurídicos e políticos. A crise sanitária desvelou a insuficiência dos valores que, até o início de 2020, empregávamos para orientar as nossas decisões cotidianas. Por isso, muitos intelectuais, advindos da Filosofia Moral, da Filosofia do Direito e da Filosofia Política, viram-se convocados a intervir no debate público, para, em um cenário de desinformação e anomia, oferecer balizas capazes de guiar o Estado e a sociedade civil. Por exemplo: pesquisadores vinculados ao campo da Bioética têm discutido quais os critérios que os médicos devem, face a escassez de recursos provocada pela superlotação dos hospitais, adotar na distribuição de leitos, respiradores etc. ${ }^{1}$ Contudo, são raras as investigações que se preocupam em destacar como marcadores sociais similares a classe, gênero e raça definem o impacto que a pandemia tem sobre diferentes populações. Ora, as desigualdades provocadas pelo classismo, pelo sexismo e pelo racismo tendem a se aprofundar, em um contexto de caos nosocômico, econômico e político. Afetam, assim, as estratégias dos "grupos vulneráveis" para se proteger do coronavírus. Abordagens que se pretendem "gerais", "neutras" e "objetivas" - e que deliberadamente ignoram as assimetrias decorrentes da discriminação - acabam por invisibilizar (e, dessa maneira, por ampliar) o sofrimento dos mais marginalizados. ${ }^{2}$ Retomando o exemplo aventado acima: parcela considerável dos professores de Bioética tem defendido que a principal regra para definir quem receberá ou não atendimento, na pandemia, deve ser a (in)existência de comorbidades (pacientes sem doenças crônicas seriam, dessa maneira, priorizados); todavia, estipular, in abstracto, tais preceitos, desconsiderando os efeitos que o racismo tem sobre a saúde pública, é uma forma de promover medidas necropolíticas. ${ }^{3}$ Privados de condições mínimas de higiene, alimentação e moradia, pretos e pardos apresentam índices maiores de comorbidades (asma

\footnotetext{
${ }^{1}$ Por todos, recomendamos a leitura do ótimo ARAÚJO, Luana Adriano; MELO, Arthur Cezar Alves de; BARBOSAFOHRMANN, Ana Paula. Critérios éticos e políticos para a triagem em tempos de crise: pensando a alocação de recursos escassos a partir da deficiência. Voluntas: Revista Internacional de Filosofia, Santa Maria, v. 11, e. 28, p. 1 a 14, julho de 2020. Disponível em: https://periodicos.ufsm.br/voluntas/article/view/43980/pdf. Acessado em: 21 de maio de 2021.

2 Sobre o tema, recomendamos a leitura de GOES, Emanuelle Freitas et al. Desigualdades raciais em saúde e a pandemia do Covid-19. Trabalho, Educação e Saúde, Rio de Janeiro, v. 18, n. 3, maio de 2020. Disponível em: https://www.scielo.br/scielo.php?script=sci_arttext\&pid=S1981-77462020000300301. Acessado em: 21 de maio de 2021. V., também, SANTOS, Márcia Pereira Alves dos et al. População negra e Covid-19: reflexões sobre racismo e saúde. Estudos Avançados, São Paulo, v. 34, n. 99, 2020. Disponível em: https://www.scielo.br/pdf/ea/v34n99/1806-9592-ea-34-99-225.pdf. Acessado em: 21 de maio de 2021.

${ }^{3}$ MBEMBE, Achille. Direito universal à respiração. Tradução de Ana L. Braga. São Paulo: n-1 edições [no 20], 2020. Disponível em: https://n-1edicoes.org/020. Acessado em: 21 de maio de 2021.
} 
severa ou moderada, doenças imunossupressoras etc.), de sorte que o critério, aparentemente técnico e imparcial, de privilegiar os mais saudáveis, pode implicar em uma exclusão sistemática dos afrodescendentes. ${ }^{4}$

A Teoria Racial Crítica (Critical Race Theory - CRT), que surgiu nas escolas de Direito mas, rapidamente, espraiou-se por outras áreas do conhecimento, talvez forneça a melhor chave de leitura para que interpretemos as relações entre o coronavírus e o racismo. Dedicada a mostrar como o discurso jurídico - "vago" e "genérico" - escamoteia e reforça a supremacia branca e a injustiça racial, a CRT permite que vejamos como políticas pretensamente globais desenvolvidas em resposta à pandemia atingem, diferentemente, brancos e não-brancos. Inúmeras categorias desenvolvidas pela CRT podem ajudar-nos a investigar o modo como o racismo estrutural se redimensiona, em tempos de crise sanitária. ${ }^{5}$

Nosso paper irá se debruçar sobre um problema específico: a maneira como, no imaginário jurídico e político de nossa civilização, grupos raciais subalternizados (negros, indígenas, asiáticos etc.) são associados a determinadas doenças. Trata-se de uma estratégia recorrente, para validar medidas de segregação e justificar o abandono estatal: populações nãobrancas começam a ser retratadas como vetores privilegiados de vírus e bactérias, mais propensos a disseminar microorganismos patogênicos (o que legitimaria a segregação), e menos propensos a apresentar sintomas advindos desses agentes (o que legitimaria o abandono estatal). ${ }^{6}$ No Brasil, inúmeras figuras públicas que, de forma ostensiva, quebraram reiteradamente a quarentena, foram às redes sociais, após contrair COVID-19, para culpabilizar seus empregados domésticos (negros, em sua maioria): essa tendência é reflexo da noção - que se encontra, vale lembrar, na contramão dos fatos históricos ${ }^{7}$ de que não-brancos seriam agentes infecciosos a serem combatidos. Ao argumentar - defendendo seu descaso quanto às medidas de prevenção - que "o brasileiro pula em esgoto e não acontece nada", o presidente Bolsonaro retoma a ideia da conaturalidade entre não-brancos e patógenos. Similarmente, nos EUA, circulou, por muitas semanas, o boato segundo o qual negros seriam imunes ao coronavírus. ${ }^{8}$ Vivendo em ambientes insalubres, pretos e pobres já teriam adquirido "anticorpos" contra boa parte das infecções, não representando públicos visados pelas políticas de saúde - mas, sim, pelas políticas de segurança pública (higienismo social), como transmissores

\footnotetext{
${ }^{4}$ CHOMILO, Nathan T. et al. The harm of a colorblind allocation of scarce resources. Health Affairs, Bethesda, 20 de abril de 2020. Disponível em: https://www.healthaffairs.org/do/10.1377/hblog20200428.904804/full/. Acessado em: 21 de maio de 2021.

${ }^{5}$ A propósito, v. BRIDGES, Khiara M. et. al. Introduction: Critical Race Theory and the Health Sciences. American Journal of Law \& Medicine, Boston, v. 43, p. 197 a 182, 2017. Disponível em http://pdfs.semanticscholar.org/e2a1/09e4437aca64f8f4d280feeaec914b473757.pdf. Acessado em: 1 de junho de 2020.

${ }^{6}$ Daí que dois médicos franceses tenham sugerido, em uma emissora de televisão, que africanos fossem utilizados como cobaias em testes de vacinas contra o coronavírus. Cf. ALVES, Toninho; FERNANDES, Renato. Imperialismo e racismo estrutural em tempos de Coronavírus. Esquerda online, Campinas, 7 de abril de 2020. Disponível em: https://esquerdaonline.com.br/2020/04/07/imperialismo-e-o-racismo-estrutural-em-temposde-coronavirus/. Acessado em: 22 de maio de 2021.

${ }^{7}$ V. DIAMOND, Jared. Armas, germes e aço: os destinos das sociedades humanas. Tradução de Silvia de Souza Costa, Cynthia Cortes e Paulo Soares. Rio de Janeiro: Record, 1997.

${ }^{8} \mathrm{Cf}$. JOHNSON, Akila; BUFORD, Talia. Early data shows african americans have contracted and died of coronavirus at an alarming rate. ProPublica, New York, 3 de abril de 2020. Disponível em: https://www.propublica.org/article/early-data-shows-african-americans-have-contracted-and-died-ofcoronavirus-at-an-alarming-rate. Acessado em: 22 de maio de 2021.
} 
de doenças. ${ }^{9}$ A doença opera, pois, como uma metáfora da segregação racial, em um sistema autocatalítico: não-brancos são, no plano simbólico, associados a microorganismos patogênicos e, no plano material, deixados à própria sorte, para enfrentar, sem apoio do Poder Público, o avanço de epidemias.

Nosso trabalho se desenvolverá em três etapas: em um primeiro momento, discutiremos, de forma ampla, as reverberações do racismo estrutural sobre a pandemia de COVID-19; em seguida, faremos uma breve apresentação da Teoria Racial Crítica (exercício que se revela necessário, considerando que se trata de uma corrente jusfilosófica ainda pouco debatida, no Brasil); por fim, recorreremos à CRT para refletir sobre como, em um imaginário social racista, populações não-brancas tendem a ser representadas como vetores de doenças. Considerando as tentativas, de governos como o britânico, o estadunidense e o brasileiro, de imputar à China a difusão do COVID-19 (chamado, por Banon, de "vírus comunista, por Bolsonaro, de "vírus chinês", e, por Trump, de "kung flu"), recorreremos à Teoria Racial Crítica Asiática - AsianCrit -, uma das inúmeras vertentes da CRT, como ponto de partida para debater a racialização da doença.

\section{CORPO COMO CAMPO DE ENFRENTAMENTOS POLÍTICOS: APARTHEID SANITÁRIO E CO- VID-19}

"Na hora da morte somos todos iguais" - o dito popular foi, ao longo do ano de 2020, reiteradamente citado, por governos e pela imprensa, como uma forma de indicar que, face à pandemia de COVID-19 que assola o planeta, as diferenças de gênero, raça e classe desapareceriam. O vice-ministro da saúde iraniano Iraj Harirch, que contraiu coronavírus, chegou a declarar: "Esse vírus é democrático e não discerne entre pobres e ricos ou entre políticos e cidadãos comuns". ${ }^{10}$ Nesse sentido, a peste se configuraria em um "grande equalizador", a lembrar-nos de que nos encontramos todos "no mesmo barco". No entanto, os parcos dados aos quais ainda temos acesso - numa era em que fake news tornaram-se política de Estado , sinalizam o contrário. Pesquisas, no Canadá e nos Estados Unidos, ${ }^{11}$ mostram que não-brancos, pobres e imigrantes foram atingidos de maneira desproporcional pela pandemia. 0

\footnotetext{
${ }^{9}$ Alguns autores têm debatido como essas campanhas de desinformação atingem, diferentemente, brancos e negros. Por todos, v. AISWAL, J. et. al. Disinformation, Misinformation and Inequality-Driven Mistrust in the Time of COVID-19: Lessons Unlearned from AIDS Denialism. Aids and Behaviour. Disponível em: https://link.springer.com/content/pdf/10.1007/s10461-020-02925-y.pdf. Acessado em: 22 de maio de 2021.

${ }^{10} \mathrm{Cf}$. LIVIO, Gustavo. A pandemia discrimina pela classe, cor, gênero e etnia. Justificando, 14 de abril de 2020. Disponível em: https://www.justificando.com/2020/04/14/a-pandemia-discrimina-pela-classe-cor-genero-eetnia/. Acessado em: 14 de agosto de 2020.

${ }^{11}$ Sobre a situação canadense, v. CHIASSON, Paul. Data linking race and health predicts new COVID-19 hotpots. The conversation, 20 de maio de 2020. Disponível em: https://theconversation.com/data-linking-race-andhealth-predicts-new-covid-19-hotspots-138579. Acessado em: 14 de agosto de 2020 . Sobre a situação estadunidense, $v$. FORD, Chandra L. Adressing inequities in the era of COVID-19: the pandemic nd the urgent need for Critical Race Theory. Family and Community Health: the jornal of health promotion \& maintenance, v. 43, n. 3, p. 184 a 186, Los Angeles, 2020. Disponível em: https://journals.Iww.com/familyandcommunityhealth/Fulltext/2020/07000/Commentary_Addressing_Inequit ies_in_the_Era_of.2.aspx. Acessado em: 14 de agosto de 2020.
} 
mesmo ocorre no Brasil. ${ }^{12} \mathrm{~A}$ desigualdade socioeconômica desdobra-se na desigualdade de acesso à saúde e aos insumos de prevenção (máscaras, álcool em gel etc.). Grupos que, no correr dos séculos, foram subalternizados pela violência (neo)colonial - negros, indígenas, aborígenes - encontram maiores dificuldades para se protegerem do coronavírus. ${ }^{13} \mathrm{Na}$ Europa e nas Américas, parcela substancial dos "trabalhadores essenciais" (que desempenham serviços, frequentemente em condições precárias, imprescindíveis à manutenção da vida social, e que, portanto, não podem ser suspensos durante a quarentena) são pretos e pardos: há levantamentos, por exemplo, que revelam que a maioria dos cuidadores e dos técnicos de enfermagem é composta por afrodescendentes. ${ }^{14}$ Negros também representam a maior porcentagem dos trabalhadores informais - diaristas, caseiros, vendedores ambulantes, figuras que compõem o chamado "precariado",$-{ }^{15}$ que, destituídos de uma rede de seguridade social, veem-se forçados a continuar em atividade. O reflexo disso é que, em diferentes países do Ocidente (como os Estados Unidos), o índice de mortandade de negros e latinos, em decorrência do COVID-19, chega a ser duas vezes maior que o de brancos. ${ }^{16}$ A Samuel Johnson, crítico literário e lexicógrafo inglês do século XVIII, atribui-se a afirmação: "Só há duas coisas certas na vida - a morte e os impostos". Valeria a pena destacar, no entanto, que ambas as coisas (a morte e os impostos), em sociedades nas quais os sistemas de justiça distributiva estão deteriorados, afetam de modos muito distintos homens e mulheres, brancos e nãobrancos, ricos e pobres.

A clássica película A máscara da morte vermelha (The Masque of the Red Death, lançada originalmente em português como A orgia da morte), filmada em 1964 sob direção do

\footnotetext{
${ }^{12}$ Sobre a situação brasileira, v. ROCHA, Camilo. O impacto do racismo estrutural nas mortes por COVID-19. Nexo, 15 de abril de 2020. Disponível em: https://www.nexojornal.com.br/expresso/2020/04/15/O-impacto-doracismo-estrutural-nas-mortes-por-covid-19. Acessado em: 14 de agosto de 2020. A propósito, recomendamos, ainda, a leitura de OLIVEIRA, Wagner Vinicius de; MARQUES, Allan Carlos da Silva. Necropolíticas em tempos de COVID-19. Justificando, 27 de abril de 2020. Disponível em: https://www.justificando.com/2020/04/27/necropoliticas-em-tempos-de-covid-19/. Acessado em: 14 de agosto de 2020.

${ }^{13} \mathrm{~A}$ propósito, recomendamos a leitura de TIMOTHY, Roberta K. Coronavirus is not the great equalizer - race matters. The conversation, 6 de abril de 2020. Disponível em: https://theconversation.com/coronavirus-is-notthe-great-equalizer-race-matters-133867. Acessado em: 14 de agosto de 2020. Especificamente no que tange à questão indígena, v. COLETTA, Amanda; TRAIANO, Heloísa. The world's indigenous peoples, with tragic history of disease, implore outsiders to keep coronavirus away. The Washington Post, 31 de março de 2020. Disponível em https://www.washingtonpost.com/world/the_americas/the-worlds-indigenous-peoples-with-tragic-historyof-disease-implore-outsiders-to-keep-coronavirus-away/2020/03/31/98597e3c-6f7f-11ea-a156-

0048b62cdb51_story.html. Acessado em: 14 de agosto de 2020.

${ }^{14} \mathrm{Cf}$. GUPTA, Tania Das. Inquiry into coronavirus nursing home deaths needs to include discussion of workersand race. The conversation, 25 de maio de 2020. Disponível em: https://theconversation.com/inquiry-intocoronavirus-nursing-home-deaths-needs-to-include-discussion-of-workers-and-race-139017. Acessado em: 14 de agosto de 2020.

${ }^{15} \mathrm{~V}$. MAYOS SOLSONA, Gonçal. Cognitariado es precariado. El cambio en la sociedad del conocimiento turboglobalizada. In: ROMÁN, B.; CASTRO, G. de (Org.). Cambio social y cooperación en el siglo XXI (vol. 2): El reto de aumentar la equidad dentro de los limites ecológicos. Barcelona: Intervida/Educo/UB, 2013. V. também SANTOS, Eneida Maria dos. As plataformas digitais de transporte e o local do negro no mercado de trabalho: o racismo nas configurações institucionais do trabalho no Brasil do século XXI. Dissertação (Mestrado em Direito) - Faculdade Nacional de Direito, Universidade Federal do Rio de Janeiro. Rio de Janeiro, 259 p. 2020.

${ }^{16} \mathrm{Cf}$. MACCOUN, Robert J. How COVID-19 deepens racial inequity in U.S. health care. Shot of Science, 27 de abril de 2020. Disponível em: https://www.annualreviews.org/shot-of-science/story/covid-19-deepens-racialinequity. Acessado em: 14 de agosto de 2020.
} 
grande cineasta Roger Corman, ${ }^{17}$ pode ajudar-nos a pensar sobre a maneira como injustiças sociais são agravadas por epidemias. No século XIV, a Morte - que se materializa como um homem trajando um manto vermelho - presenteia uma velha camponesa com uma rosa branca, que, repentinamente, torna-se rubra. A mulher vê-se infectada por uma nova doença, que rapidamente alastra-se por toda a aldeia. O príncipe Próspero (personagem criado à imagem e semelhança do protagonista da peça A tempestade, de Shakespeare), tomando ciência dos acontecimentos, incendeia a vila (e seus habitantes), como forma de retardar o avanço da praga. Em seguida, acompanhado de cortesãos, refugia-se por trás dos muros de um enorme castelo, onde, à distância, assiste o drama de seus súditos. A Danse Macabre, ${ }^{18}$ ciranda da morte para a qual nobres e plebeus, clérigos e leigos, camponeses e citadinos são arrastados, fatalmente irromperá pelas portas do palácio de Próspero - daí que o filme se encerre com o brocardo latino Sic transit gloria mundi, isto é, "assim transita a glória do mundo", ou ainda, "todas as glórias do mundo são transitórias". Contudo, entre as mortes da camponesa e do príncipe, entre o início e o fim da epidemia, existe um lapso temporal, um delay, no qual as injustiças sociais se dão: enquanto os nobres refestelam-se em banquetes, brincam, cantam e dançam, os servos da gleba morrem à míngua. É sobre esse lapso temporal, que adia a morte de uns enquanto adianta a de outros, que precisamos meditar, em uma reflexão racializada sobre o coronavírus.

Como a antropóloga Rosana Pinheiro-Machado salienta, em 2020 restou explicitado o "apartheid sanitário" no qual vivemos. ${ }^{19} \mathrm{O}$ coronavírus ensina-nos que problemas de saúde não são realidades exclusivamente médicas, mas também jurídicas e políticas. ${ }^{20}$ Toda doença configura-se em um fenômeno, a um só tempo, natural e cultural. E isso porque a relação de um indivíduo com seu corpo é, sempre, mediada pela cultura na qual ele se insere. ${ }^{21}$ Nossa percepção do que vem a ser um corpo normal e um corpo anormal, um corpo saudável e um corpo doente, é filtrada pelo "horizonte de sentido" (na acepção gadameriana da expressão) em que nos achamos imersos. ${ }^{22}$ Males como a lepra, a tuberculose, a sífilis e a aids investem-

\footnotetext{
${ }^{17} \mathrm{O}$ filme baseia-se em POE, Edgar Allan. A máscara da morte rubra. In: Histórias extraordinárias. Tradução de José Paulo Paes. São Paulo: Companhia das Letras, 2008.

${ }^{18}$ Sobre a alegoria da Danse Macabre na Idade Média, recomendamos a leitura de SCHMITT, Juliana. A morte e a sociedade nas danças macabras medievais. Poéticas visuais, Bauru, v. 7, n. 1, p. 14 a 28, 2016. Disponível em: http://www.poeticasvisuais.com.br/wp-content/uploads/2017/03/V7N1-Artigos.pdf. Acessado em: 14 de agosto de 2020.

${ }^{19}$ PINHEIRO-MACHADO, Rosana. Coronavírus não é democrático: pobres, precarizados e mulheres vão sofrer mais. The Intercept Brasil, 17 de março de 2020. Disponível em: https://theintercept.com/2020/03/17/coronavirus-pandemia-opressao-social/. Acessado em: 14 de agosto de 2020.

${ }^{20} E$ este o cerne da argumentação de SANTOS, Boaventura de Souza. A cruel pedagogia do vírus. Boitempo: São Paulo, 2020.

${ }^{21}$ Um exemplo da imbricação entre corpo e cultura pode ser extraído da obra da pensadora nigeriana Oyèrónkẹ Oyěwùmí. Oyěwùmí mostra como o bimorfismo sexual (isto é, a existência de órgãos reprodutores distintos, em machos e fêmeas da espécie humana) não se torna, necessariamente, base para a construção de papeis sociais diferenciados. Analisando a cultura iorubá pré-colonial, Oyěwùmí observará que as representações do "homem" e da "mulher", tal como tipificadas no Ocidente, inexistiam na Nigéria. V. OYĚWÙMí, Oyeronke. The Invention of Women: Making an African Sense of Western. Gender Discourses. Minneapolis: University of Minnesota Press, 1997.

${ }^{22}$ Sobre o tema, recomendamos a leitura do clássico CANGUILHEM, Georges. O normal e o patológico. Tradução de Maria de Threza Redig de C. Barrocas e Luiz Octávio F. B. Leite. 5. ed. Rio de Janeiro: Forense Universitária, 2002. Gadamer, ele próprio, escreverá sobre a noção de saúde a partir da hermenêutica fenomenológica, em GADAMER, Hans-Georg. O caráter oculto da saúde. Tradução de Antônio Luz Costa. Petrópolis: Vozes, 2006.
} 
se de diferentes cargas simbólicas, a depender do lugar e do momento. ${ }^{23}$ No âmbito dessa discussão, A doença como metáfora, texto publicado por Susan Sontag em 1978, talvez seja uma das referências seminais. ${ }^{24}$ Sontag, ao longo da vida, lutou reiteradas vezes contra o câncer; ${ }^{25}$ em meio aos tratamentos, deu-se conta de que o uso do termo "câncer", em nossa sociedade, como metáfora para descrever infortúnios de toda ordem - "racismo é um câncer social" etc. - terminava por reforçar a estigmatização dos pacientes oncológicos. Essa compreensão serviu de ponto de partida para que Sontag desenvolvesse um ensaio sobre as representações de diferentes doenças em nosso imaginário social - e sobre o uso político-estratégico dessas representações, na segregação de grupos específicos. Na esteira de Sontag, podemos intuir que o corpo recebe, em conjunturas diversas, diferentes valorações: é valorizado ou desvalorizado, patologizado ou despatologizado, tornando-se, assim, um campo de enfrentamentos políticos. Em nossa civilização, o homem branco heterossexual cisgênero sem deficiência é assumido como paradigma; todos os demais (mulheres, não-brancos, homossexuais etc.) são encarados como "aberrações", sujeitos, portanto, a controle clínico e policial. ${ }^{26}$ Nessa conjuntura, não é difícil concluir que as discriminações baseadas em gênero, raça, classe, orientação sexual e habilidades físicas e intelectuais irão modular a forma como uma epidemia é vivenciada por parcelas específicas da população. Setores vulnerabilizados estão, não apenas mais expostos ao vírus, mas, também, menos protegidos face a intervenções estatais arbitrárias (detenção, prisão, internação forçada) feitas em nome da saúde pública. ${ }^{27}$

É crescente a literatura destinada a investigar a dimensão socioeconômica e política da crise gerada pelo coronavírus. ${ }^{28}$ Um tema recorrente (um tópos, diríamos), nessa literatura, é a tese de que as dinâmicas neoliberais, fortalecidas nos últimos anos com a emergência de governos de extrema direita, atuariam para catalisar os efeitos nefastos da pandemia. ${ }^{29} \mathrm{~A}$ erosão dos serviços públicos - em virtude de uma acentuada redução dos investimentos em educação, saúde e previdência social - fragiliza a situação daqueles cujas rendas encontramse nos estratos mais baixos. ${ }^{30}$ Ora, o neoliberalismo - à diferença do liberalismo clássico -

\footnotetext{
${ }^{23}$ Gilberto Freyre, por exemplo, dedica algumas páginas do clássico Casa grande \& Senzala para descrever como, junto às famílias senhoriais do Brasil escravocrata, as marcas de sífilis eram vistas como um sinal de ingresso na vida adulta, um indicativo de "virilidade". FREYRE, Gilberto. Casa Grande \& Senzala: formação da família brasileira sob regime de economia patriarcal. São Paulo: Global, 2005

${ }^{24} \mathrm{~V}$. SONTAG, Susan. A doença como metáfora. Tradução de Márcio Ramalho. Rio de Janeiro: Graal, 1984.

${ }^{25} \mathrm{~A}$ respeito da luta de Sontag contra o câncer, recomendamos a leitura de RIEFF, David, Swimming in a Sea of Death: A Son's Memoir. New York: Simon \& Schuster, 2008.

${ }^{26}$ Sobre o tema, recomendamos a leitura do já clássico FOUCAULT, Michel. Nascimento da clínica. Tradução Roberto Machado. Rio de Janeiro: Forense Universitária, 1987.

${ }^{27}$ No Canadá, por exemplo, é desproporcional o número de homens negros condenados por propagação de doença contagiosa (notadamente no que diz respeito à aids). A mídia produz uma "hipersexualização" dos homens negros, representados, não só como estupradores em potencial, mas como principais vetores de disseminação de doenças sexualmente transmissíveis. A propósito, v. DUBE, Sané. Skewed stories. Catie: Canada's source for HIV and hepatites C information, verão de 2017. Disponível em https://www.catie.ca/en/positiveside/summer-2017/skewed-stories. Acessado em: 14 de agosto de 2020.

${ }^{28}$ A título de exemplo, podemos citar a coletânea GONÇALVES, Guilherme Leite (Org.). Covid-19, capitalismo e crise: bibliografia comentada. Rio de Janeiro: LEICC/Revista Direito e Práxis, 2020.

${ }^{29}$ A propósito, v. ZIZEK, Slavoj. Pandemia: COVID-19 e a reinvenção do comunismo. São Paulo: Boitempo, 2020.

${ }^{30} \mathrm{~A}$ propósito, $v$. VOMMARO, Pablo. O mundo em tempos de pandemia: certezas, dilemas e perspectivas. Direito \& Práxis, Ahead of Print, Rio de Janeiro, 2020. Disponível em:https://www.epublicacoes.uerj.br/index.php/revistaceaju/article/view/51001/33840. Acessado em: 15 de agosto de 2020.
} 
calca-se na primazia da concorrência sobre a solidariedade. ${ }^{31}$ Aproximando-se do darwinismo social (tal como postulado, no século XIX, por figuras como Herbert Spencer), ${ }^{32}$ o discurso neoliberal defende que a livre competição por recursos vitais, entre os homens, implica, a longo prazo, no aperfeiçoamento da sociedade: os espécimes mais fracos (isto é, sem "espírito empreendedor") irão perecer, enquanto os mais fortes se multiplicarão. Assim, programas de justiça social devem ser combatidos, pois permitem que "malandros" e "indolentes" subsistam, o que retardaria o advento do Novo Homem. Para o neoliberalismo, é ao indivíduo, exclusivamente, que deve ser imputado o sucesso ou o fracasso de sua existência: desemprego, pobreza e doença surgem devido a "cálculos errados", e as perdas que um sujeito venha a ter em decorrência deles não podem, jamais, ser socializadas. Todo ser humano seria "empreendedor de si mesmo" - e, na condição de "empreendedor", arcaria sozinho com os riscos associados a sua vida e ao seu labor. É essa a lógica subjacente ao fenômeno da uberização. ${ }^{33}$ Nesse cenário, a pandemia seria, não uma tragédia, mas uma oportunidade, instrumento capaz de separar o joio do trigo, os que merecem e os que não merecem sobreviver. Daí que Débora Diniz fale em "necropolítica das epidemias", 34 em uma tentativa de refletir sobre o esforço que alguns governos têm empreendido para "naturalizar o risco de vida" (na expressão usada por Juliana Pinho, comunicadora popular do complexo de favelas da Maré), ao invés de financiar medidas capazes de minimizar o número de mortos e infectados. ${ }^{35}$

"Não podemos permitir que a cura seja pior do que o próprio problema" - a observação, do presidente norte-americano Donald Trump, constitui-se em um convite para que sacrifiquemos, em honra à economia concorrencial, fracos, idosos e doentes. Por trás da tese da "imunidade de rebanho", insinua-se a crença, spenceriana, de que ações de solidariedade são obstáculos ao progresso material, e de que o "livre mercado" deve prevalecer sobre qualquer compromisso cívico. Neoliberalismo, darwinismo social e racismo estrutural caminham, no

\footnotetext{
${ }^{31}$ Sobre as diferenças entre o liberalismo clássico e o neoliberalismo, remetemos à obra DARDOT, Pierre; LAVAL, Christian. A nova razão do mundo: ensaio sobre a sociedade neoliberal. Tradução de Mariana Echalar. São Paulo: Boitempo, 2016.

${ }^{32} \mathrm{Cf}$. SPENCER, Herbert. The man versus the State: with six essays on government, society, and freedom. Indianapolis: Liberty Fund, 1982.

${ }^{33}$ Sobre a uberização, v. PINHEIRO, Silvia Silva Martins; SOUZA, Márcia de Paula; GUIMARÃES, Karoline Claudino. Uberização: trabalho do capitalismo contemporâneo. Revista Serviço Social em Debate, Belo Horizonte, v. 1, n. 2, p. 53 a 68, 2018. Há décadas, o economista John Kenneth Galbraith já denunciava a maneira como, no capitalismo tardio, a lógica empresarial tendia a invadir a esfera das relações sociais. A propósito, v. GALBRAITH, John Kenneth. A era da incerteza. Tradução de F. R. Nickelsen Pellegrini. São Paulo: 1986. O filósofo Byung-Chul Han tem, em incontáveis obras, especulado sobre a forma como o processo de uberização tem gerado novas violências. A esse respeito, v. HAN, Byung-Chul. Topologia da violência. Tradução de Enio Paulo Giachini. Petrópolis: Vozes, 2017.

${ }^{34}$ Cf. DINIZ, Débora. A necropolítica das epidemias. El País, 9 de março de 2020. Disponível em https://brasil.elpais.com/opiniao/2020-03-09/a-necropolitica-das-epidemias.html. Acessado em: 15 de agosto de 2020. O conceito de 'necropolítica' tem se popularizado nos últimos anos. Foi cunhado pelo filósofo camaronês Achille Mbembe, em um esforço para discutir os limites da noção foucaultiana de biopolítica, bem como da distinção schmittiana entre Estado de Direito e Estado de Exceção, na análise da realidade social de países neocoloniais, nos quais dá-se uma "guerra estrutural" permanente entre o Poder Público e a sociedade civil, que justifica uma contínua suspensão de garantias e liberdades fundamentais. Sobre o tema, v. MBEMBE, Achille. Necropolítica. Tradução de Renata Santini. São Paulo: N-1, 2019.

${ }^{35} \mathrm{Uma}$ brilhante reflexão sobre as medidas que poderiam ser tomadas pelo Estado para reduzir o risco de morte, durante a pandemia, pode ser encontrada em MARQUES, Victor Ximenes. Pandemia e antiguerra: da lógica da acumulação à lógica do cuidado. Voluntas: Revista de Filosofia, Santa Maria, v. 11, p. 1 a 11, julho de 2020. Disponível em: https://periodicos.ufsm.br/voluntas/article/view/44015/pdf. Acessado em: 15 de agosto de 2020
} 
mundo contemporâneo, de mãos dadas: hierarquizações sociais (como aquelas que advêm das diferenças de oportunidades conferidas a brancos e negros, em contextos pós-escravistas) são justificadas como resultantes da "seleção natural" promovida pelo mercado. Nesse sentido, se pretos e pardos constituem a maior parcela da população desempregada e subempregada, isso decorreria, única e exclusivamente, de sua própria "inaptidão natural" para o exercício de atividades qualificadas. Da mesma maneira, se encontram-se entre as maiores vítimas do COVID-19, deveriam ser os únicos responsabilizados. O modo como essa retórica se infiltrou na discussão sobre a quarentena torna urgente a necessidade de trabalhos que racializem a interpretação sobre as implicações políticas da pandemia. É o que nos propomos a fazer no presente paper, à luz da Teoria Racial Crítica.

\section{UMA BREVE HISTÓRIA DA TEORIA RACIAL CRÍTICA}

"Basta que o Direito não seja racista? Ou é preciso que ele seja antirracista?" Tais questionamentos - livremente inspirados em observação da célebre filósofa Angela Davis - poderiam servir para sintetizar os temas e os problemas centrais enfrentados pela Teoria Racial Crítica, movimento intelectual que germinou nas universidades estadunidenses durante a década de $1980 .{ }^{36}$ O formalismo jurídico, perspectiva ainda hegemônica entre os operadores do Direito, ancora-se na ideologia liberal, e parte do pressuposto de que o ordenamento deve ser "neutro", não fazendo acepção de pessoas. Ao dirigir-se a todos indistintamente - ignorando as condições materiais concretas de cada sujeito -, a norma jurídica, geral e abstrata, garantiria a igualdade formal, trunfo do Estado contemporâneo sobre as sociedades estamentais do Antigo Regime. Mas e se a pretensa "neutralidade" do Direito liberal funcionasse para escamotear, legitimar e reforçar hierarquizações sociais injustas? E se a igualdade formal trabaIhasse em prol da manutenção de desigualdades materiais? São essas indagações que levaram ao surgimento da CRT. ${ }^{37}$

O caso Brown v. Board of Education, que se desenrolou entre 1952 e 1954 - mas cujas implicações se fazem sentir até hoje -, foi evento histórico fundamental para que juristas nãobrancos (nativos, latinos, asiáticos, e, em especial, afroamericanos) começassem a elaborar um projeto teórico antiformalista, dedicado a denunciar os vínculos subterrâneos entre juspositivismo e racismo estrutural. ${ }^{38}$ No caso Brown, a Suprema Corte dos Estados Unidos entendeu, revertendo a decisão tomada, no ano de 1896, em Plessy v. Ferguson, que as políticas

\footnotetext{
${ }^{36}$ Uma introdução à Teoria Racial Crítica pode ser encontrada em DELGADO, Richard; STEFANIC, Jean. Critical Race Theory: an Introduction. New York; London: New York University Press, 2001. Uma reflexão jusfilosófica a respeito das premissas do movimento é desenvolvida em HARRIS, Angela P. The Jurisprudence of Reconstruction. California Law Review, Berkeley, v. 84, n. 4, julho de 1994, p. 741 a 785. Sobre a aplicabilidade de categorias da Teoria Racial Crítica na análise da conjuntura sociopolítica brasileira, v. SILVA, Caroline; PIRES, Thula. Teoria Crítica da Raça como referencial teórico necessário para pensar a relação entre direito e racismo no Brasil. XXVI CONPEDI. Florianópolis, 2015. Sobre a história da CRT, v. CRENSHAW, Kimberlé Williams. Twenty Years of Critical Race Theory: Looking Back to Move Foward. Connecticut Law Review, v. 43, n. 5, Storrs, p. 1253 a 1349, julho de 2011.

${ }^{37}$ Sobre o despontar da CRT, recomendamos a leitura de FERREIRA, G.; QUEIROZ, M. A trajetória da Teoria Crítica da Raça: história, conceitos e reflexões para pensar o Brasil. Teoria Jurídica Contemporânea, Rio de Janeiro, v. 3, n. 1, p. 201 a 229, 2018.

${ }^{38}$ Há vasta bibliografia sobre Brown v. Board of Education. Por todas, recomendamos a leitura da obra BELL, Derrick (Org.). Silent Covenants: Brown v. Board of Education and the Unfulfilled Hopes for Racial Reform. Oxford: Oxford University Press, 2004.
} 
de segregação racial nas escolas norte-americanas (que podiam, por exemplo, proibir a matrícula de crianças negras) violavam a cláusula de igual proteção da 14a Emenda da Constituição. Conquista do movimento dos direitos civis, o julgado lançou uma pá de cal sobre a doutrina "Separados, mas iguais", e representou o início do fim das Leis Jim Crow, que validavam o apartheid na sociedade estadunidense. ${ }^{39} \mathrm{O}$ caso Brown foi celebrado, por pensadores liberais, como um símbolo da aptidão do Ocidente capitalista para incluir minorias, garantindo a todos as mesmas oportunidades. Todavia, no curso dos anos, a comunidade negra começou a darse conta de que a abolição de normas discriminatórias, no Direito, não implicava necessariamente no fim de práticas racistas, na vida cotidiana. ${ }^{40}$ Nesse sentido, Brown v. Board of Education, como mecanismo de balanceamento das desigualdades raciais, teria fracassado, constituindo-se em uma transformação sem mudança real. A realidade educacional é sintomática. Formalmente "mistos", os colégios norte-americanos seguem sendo, em muitas cidades, drasticamente segregados. Isso porque, frequentemente, os bairros nos Estados Unidos são racialmente demarcados, e regulamentos administrativos proíbem que os pais matriculem seus filhos em instituições fora de suas vizinhanças. As escolas em bairros não-brancos recebem, via de regra, menos investimentos públicos, o que se reflete em desempenho mais fraco dos alunos. Assim, a igualdade formal de oportunidades não gera igualdade de resultados, e valida um sistema que segue sendo profundamente assimétrico. ${ }^{41}$

Juspositivistas defendem que a hermenêutica constitucional consolidada após o caso Brown, calcada na "cegueira da cor" (racial color blindness, expressão frequentemente traduzida, também, como "daltonismo racial"), seria o suficiente para instituir uma sociedade sem discriminação. ${ }^{42}$ Para o Estado, todas as identidades raciais seriam "simétricas", de sorte que políticas baseadas na cor - ainda que orientadas por um esforço para retificar injustiças históricas cometidas no seio de uma cultura pós-escravista - deveriam ser coibidas. Teríamos, assim, um Direito não-racista - mas, não, um Direito antirracista. Ao longo do tempo, juristas vinculados à Teoria Racial Crítica atentaram para o fato de que, subjacente à "neutralidade" do ordenamento jurídico, o privilégio da branquitude perdurava. Ignorando o impacto que, no Ocidente, a raça teve e tem na distribuição de poder e recursos, o Direito "cego à cor" fortaleceria um racismo inconsciente e um senso implícito da posição dos brancos. ${ }^{43}$ Como observa Derrick Bell, um dos pioneiros da CRT: "A cegueira da cor é adotada como uma via fácil para

\footnotetext{
${ }^{39} \mathrm{Cf}$. KLARMAN, Michael. From Jim Crow to Civil Rights: the Supreme Court and the Struggle for Racial Equality. Oxford: Orxford University Press, 2004.

${ }^{40}$ Sobre o tema, v. PATTERSON, James T. Brown v. Board of Education: A Civil Rights Milestone and Its Troubled Legacy. Oxford: Oxford University Press, 2001.

${ }^{41}$ Como Carlo A. Pedrioli observa, em comentário à obra A Civil Rights Milestone and Its Troubled Legacy (do historiador James T. Patterson), em 1998-1999, 90\% das crianças nas escolas públicas de Chicago eram negras ou hispânicas; nas escolas públicas de Detroit, $90 \%$ das crianças eram negras. O caso Freeman v. Pitts permitiu que decisões "privadas" conduzissem a um processo de ressegregação. Nesse sentido, talvez uma decisão que ampliasse o financiamento público das escolas frequentadas por crianças não-brancas tivesse efeitos mais positivos que o caso Brown.Cf.PEDRIOLI, Carlo A. Under a Critical Race Theory Lens - Brown v. Board of Education: A Civil Rights Milestone and Its Troubled Legacy. African-American Law \& Policy Report, Berkeley, v. VII, p. 93 a $106, \quad$ maio de $2005 . \quad$ Disponível em https://lawpublications.barry.edu/cgi/viewcontent.cgi?article=1032\&context=facultyscholarship. Acessado em: 6 de junho de 2020.

${ }^{42}$ Uma análise crítica dessa perspectiva pode ser encontrada em GOTANDA, Neil. A Critique of "Our Constitution is Color-Blind". Stanford Law Review, Stanford, v. 44, n. 1, p. 1 a 68, novembro de 1991.

${ }^{43}$ Cf. BROOKS, Roy L. Brown v. Board of Education Fifty Years Later: A Critical Race Theory Perspective. Howard Law Journal, Washington, v. 47, n. 3, p. 581 a 626, primavera de 2004.
} 
encobrir as questões raciais que a nação prefere não enfrentar, e muito menos tentar solucionar, seriamente". ${ }^{44}$ Ora, contra a retórica integracionista - segundo a qual viveríamos em um sistema meritocrático, onde o talento preponderaria sobre a origem, a raça, o sexo, a cor, a idade etc. -, a CRT procura mostrar a persistência, em uma sociedade aparentemente inclusiva, de estruturas de subordinação e exploração. Autores liberais tendem a interpretar a história do constitucionalismo moderno, da Revolução Francesa aos nossos dias, como uma trajetória, gradual e progressiva, de expansão e aprofundamento de liberdades e garantias. Mais direitos, para mais pessoas, em um processo contínuo de aperfeiçoamento. ${ }^{45}$ Esposando uma visão "cínica" do Direito pós-colonial, a CRT sugerirá que os "avanços históricos" no reconhecimento de direitos aos excluídos derivam, na verdade, das tentativas da elite de, sem desestabilizar a ordem vigente, "acomodar" as demandas sociais de modo a postergar indefinidamente o enfrentamento aos privilégios. ${ }^{46}$

Bell sumarizará essa proposta de leitura formulando o princípio da convergência de interesses. ${ }^{47}$ Conforme Bell, no correr da história americana, interesses da comunidade afrodescendente só eram atendidos quando coincidiam com (ou conformavam-se aos) interesses da comunidade eurodescendente. $O$ reconhecimento de direitos aos negros deveria harmonizarse ao status quo, maximizando os benefícios e minimizando os prejuízos dos brancos. ${ }^{48}$ É a partir dessa grelha analítica que Bell compreende, por exemplo, a Proclamação de Emancipação de 1863 - que, ao converter a guerra pela unificação dos Estados Unidos em uma cruzada moral pela libertação dos escravizados do Sul, angariou a simpatia dos negros livres do Norte, que reforçaram as frentes de batalha. É nessa chave, ainda, que Bell enxergará o caso Brown. Na Guerra Fria, as Leis Jim Crow prejudicariam a imagem dos Estados Unidos junto a países do sul global. Nesse sentido, o fim das políticas de segregação, na década de 1950, teria como principal objetivo, não melhorar as condições de vida dos negros, mas ampliar, na luta contra a União Soviética, a esfera de influência norte-americana na África, na Ásia e na América Latina. Nas palavras de Bell:

Brown não foi uma decisão revolucionária. Ela é, pelo contrário, o exemplo definitivo de que o interesse dos negros em obter justiça racial é acomodado apenas quando - e enquanto - os legisladores acham que o interesse dos negros converge com os interesses políticos e econômicos dos brancos. ${ }^{49}$

\footnotetext{
${ }^{44}$ Tradução nossa para: "Color-blindness is adopted as an easy way to cover over racial issues with wich the nation would rather not wrestle, much less try seriously to resolve". BELL, Derrick. The Unintended Lessons in Brown v. Board of Education. NYLS Law Review, New York, v. 49, n. 4, p. 1053 a 1067, janeiro de 2005, p. 1066.

${ }^{45} \mathrm{~A}$ tese da geração de direitos fundamentais, proposta por Karel Vasak e desenvolvida por Norberto Bobbio, exemplifica essa posição. $V$. BOBBIO, Nroberto. A era dos direitos. Tradução de Carlos Nelson Coutinho. Rio de Janeiro: Elsevier, 2004. Sobre o tema, v., também, HUNT, Lynn. A invenção dos direitos humanos: uma história. Tradução de Rosaura Eichenberg. São Paulo: Companhia das Letras, 2009.

${ }^{46}$ V. HARRIS, Angela P. Compassion and Critique. Columbia Journal of Race and Law, New York, v. 1, n. 3, p. p. 326 a 352, 2012.

${ }^{47} \mathrm{~V}$. BELL, Derrick. Brown v. Board of Education and the Interest Convergence Dilemma. Harvard Law Review, v. 93, n. 1, Cambridge, p. 518 a 533, janeiro de 1980.

${ }^{48} \mathrm{~A}$ propósito, recomendamos a leitura do já clássico BELL, Derrick. Race, Racism, and American Law. Boston: Little and Brown, 1973.

${ }^{49}$ Tradução nossa para: "Brown was not a revolutionary decision. Rather, it is the definitive example that the interest of blacks in achieving racial justice is accomodated only when and for so long as policymakers find that the interest of blacks converges with the political and economic interests of whites". BELL. The Unintended Lessons in Brown v. Board of Education..., cit., p. 1056.
} 
Para Bell, o racismo é elemento central, normal e permanente da sociedade norteamericana - e da civilização ocidental, como um todo. ${ }^{50}$ Dessa maneira, condutas discriminatórias, da parte de agentes privados ou públicos, não se constituiriam em "acidentes", a serem corrigidos através de reformas pontuais em nossa arquitetura jurídico-institucional. No entendimento de Bell, o desenvolvimento de uma cultura pós-racial pressuporia uma radical revisão das bases que pavimentam a moderna sociedade de mercado - a ideia de um "capitalismo com face humana", inclusivo e democrático, representaria um mito. ${ }^{51} \mathrm{O}$ trabalho de Bell - e da CRT, de forma geral - é marcadamente influenciado pelas escolas de pensamento jurídico crítico que despontaram a partir da década de 1960, sob o impacto da Nova Esquerda, da contracultura, do movimento hippie, da descolonização da Ásia e da África etc. ${ }^{52}$ A CRT é tributária, em especial, dos Critical Legal Studies (CLS), corrente justeórica que, fundada pelo filósofo brasileiro Roberto Mangabeira Unger, consolidou-se em Harvard e em Yale, nos anos 1980. ${ }^{53}$ É dos CLS que a CRT herda a crença de que, sob a generalidade - a "indeterminação", para valermo-nos do jargão dos crits ${ }^{54}$ - do discurso jurídico, escondem-se ambições classistas (direcionadas à perpetuação do abismo entre pobres e ricos). Segundo os CLS, é impossível compreender, plenamente, o ordenamento jurídico contemporâneo sem conhecer a dinâmica capitalista que lhe serve de sustentáculo. ${ }^{55} \mathrm{~A} C R T$, todavia, pretende dar um passo além dos CLS: defende que, para compreender a dinâmica capitalista, é preciso conhecer os fundamentos racistas da sociedade moderna. ${ }^{56}$ Não se trata de instaurar uma "competição de opressões", mas de indicar como, historicamente, desigualdades socioeconômicas incidiram de maneira diversa sobre diferentes grupos étnicos. Modernidade é colonialidade: a divisão internacional do trabalho inaugurada, no século XVI, pelas Grandes Navegações, valeu-se da ideia de 'raça' como critério central para o reparto de bens e funções. Negros, ameríndios e aborígenes foram - na gramática de Eduardo Galeano - o primeiro "proletariado externo" do Ocidente capitalista, lançados, desde então, às margens do sistema-mundo. Logo, as lutas antiformalista, anticapitalista, antirracista e anticolonialista devem conjugar-se e imbricar-se.

\footnotetext{
${ }^{50}$ Essa consciência atravessa as inúmeras crônicas que compõem o livro BELL, Derrick. Faces at the Bottom of the Well: the permanence of racism. New York: BasicBooks, 1992.

${ }^{51}$ Sobre a necessidade de erigir um novo projeto civilizatório, pós-racial, pós-moderno e pós-capitalista, $v$. HARRIS, Angela. Jurisprudence of Reconstruction. California Law Review, Palo Alto, v. 82, n. 4, p. 741 a 785, julho de 1994.

${ }^{52}$ Uma breve descrição dessas escolas é apresentada em WOLKMER, Antonio Carlos. Introdução ao pensamento jurídico crítico. São Paulo: Saraiva, 2002.

${ }^{53}$ Sobre a trajetória dos Critical Legal Studies, recomendamos a leitura de UNGER, Roberto Mangabeira. The Critical Legal Studies Movement: another time, a greater risk. London; New York: Verso, 2015. Cf., também, ALMEIDA, Philippe Oliveira de. O neoliberalismo e a crise dos Critical Legal Studies. Revista Direito e Práxis, Rio de Janeiro, v. 9, n. 4, p. 2229 a 2250, 2018.

${ }^{54}$ Nome dado aos membros dos Critical Legal Studies.

${ }^{55} \mathrm{Cf}$. KENNEDY, Duncan. Legal education and the reproduction of hierarchy: a polemic against the system. New York: New York Press, 2007.

${ }^{56}$ Sobre a "passagem" dos CLS à CRT, v. BRACAMONTE, Jose A. Minority critiques of the Critical Legal Studies Movement. Harvard Civil Rights-Civil Liberties Law Review, Cambridge, v. 22, n. 1, p. 297 a 299. Cf., também, ALMEIDA, Philippe Oliveira de. Intersecções entre Direito, raça e deficiência: a proposta da DisCrit. BARBOSAFOHRMANN, Ana Paula; MARTINS, Guilherme Magalhães (Org.). Pessoa com deficiência: estudos interdisciplinares. Indaiatuba: Editora Foco, 2020.
} 
A CRT traz uma proposta alternativa para se pensar, praticar e ensinar o Direito. ${ }^{57} \mathrm{~A}$ invisibilização das diferenças, no pensamento jurídico, longe de evitar discriminações, serviu para reforçar ideologias dominantes; a CRT, com o fito de desmantelar semelhantes estratégias de poder, pretende resgatar as vozes das "pessoas de cor" marginalizadas. ${ }^{58}$ O Direito é, no mais das vezes, pensado, praticado e ensinado por homens brancos heterossexuais cisgêneros sem deficiência e de classe média alta; tendemos, assim, a identificar a perspectiva desse grupo (pequeno, se comparado à população mundial) como paradigmática. Assim, quando falamos em um entendimento "neutro", universal e não-seccionado da realidade jurídica, temos em mente, na verdade, a visão parcial, relativa e seccionada que os homens brancos heterossexuais etc. produzem. Naturalizamos, normalizamos e generalizamos essa visão, face à qual outras vivências do Direito - de mulheres negras pobres, por exemplo - são retratadas como "exceções", "nuances", "variações". ${ }^{59}$ O poeta e pintor inglês William Blake disse, certa feita: "uma só lei para o leão e o boi é opressão". Na esteira de Blake, o escritor francês Anatole France ironizou: "a lei, na sua majestosa igualdade, proíbe ao rico e ao pobre de furtarem pão e dormirem debaixo da ponte, e permite a ambos que se hospedem no Hotel Ritz".

A "cegueira da cor", no debate jurídico, tem efeitos perversos, à medida que oculta os saberes e as experiências de grupos não-brancos. É o que explica que, num país como o Brasil - onde parcela substantiva da população reside em favelas (algumas, mesmo, construídas em palafitas!) -, nossos juristas produzam tanto material bibliográfico sobre aquisição de propriedade por aluvião, e tão pouco sobre o "puxadinho" e o direito real de laje. É o que permite, ainda, entender a razão de, sob a égide da Lei de Drogas - em sua neutralidade, em sua generalidade e em sua indeterminação -, negros com algumas gramas de maconha serem classificados como "traficantes", enquanto brancos com toneladas de cocaína são considerados "usuários".

O colonialismo mental reifica identidades, universalizando o horizonte do branco e particularizando (guetificando, caricaturizando como "exótico" e "pitoresco") o horizonte dos não-brancos. O negro precisa "nomear a própria realidade", autodefinir-se, construir um vocabulário que descreva as circunstâncias que o rodeiam - do contrário, valendo-se das categorias "universalizáveis" gestadas por um saber eurocentrado, terminará, involuntariamente, legitimando o poder que procura condenar. ${ }^{60}$ Por isso, muitos juristas associados à CRT - como Patricia J. Williams, Kimberlé Crenshaw, Mari Matsuda e Angela P. Harris ${ }^{61}$ recorrerão com frequência a crônicas, testemunhos e relatos de experiência, produzindo empatia, desconforto etc. ${ }^{62}$ Se a linguagem "impessoal" e "racionalizada" da Ciência do Direito hegemônica

\footnotetext{
${ }^{57}$ Sobre os pressupostos epistemológicos da CRT, cf. VALDES, Francisco. Latina/o Ethnicities, Critical Race Theory, and Post-Identity Politics in Postmodern Legal Culture: From Practices to Possibilities. La Raza Law Journal, v. 9, n. 1, p. 1 a 31, 1996.

${ }^{58} \mathrm{Cf}$. POWERS, Peter Kerry. A ghost in the collaborative machine: the White male teacher in the multicultural classroom. In: TUSMITH, Bonnie; REDDY, Maureen T. (Org.). Race in the College Classroom: pedagogy and politics. New Brunswick, New Jersey, London: Rutgers University Press.

${ }^{59}$ Daí a importância da discussão sobre "lugar de fala". Para uma introdução ao tema, v. RIBEIRO, Djamila. Lugar de fala. São Paulo: Sueli Carneiro; Pólen, 2019.

${ }^{60}$ É essa a coluna vertebral da obra do Dr. Carter G. Woodson, central para o delineamento da Teoria Racial Crítica. Cf. WOODSON, Carter G. The Mis-Education of the Negro. Trenton: Africa World Press, 1998.

${ }^{61}$ Por todos, $v$. WILLIAMS, Patricia J. The alchemy of race and rights: diary of a Law Professor. Cambridge: Harvard University Press, 1992.

${ }^{62}$ Cf.LAC, Van T. In Real Time: From Theory to Practice in a Critical Race Pedagogy Classroom. i. e.: inquiry in education, Chicago, v. 9, n. 1, p. 1 a 21, 2017.
} 
camufla os preconceitos e as pretensões de um segmento circunscrito da comunidade, o discurso em primeira pessoa, franco e passional, da CRT manifesta-se como um desmascaro, um desbunde, que repolitiza o debate jurídico - ao mostrar como suas pseudo-tecnicidades estão atravessadas por sonhos, desejos, anseios e temores de indivíduos concretos, historicamente situados, inseridos em loci específicos no âmbito dos conflitos sociais.

Embora tenha surgido como um instrumento para escrutinar a cena jurídico-política dos Estados Unidos pós-segregação, a Teoria Racial Crítica pode ser utilizada para que reflitamos sobre o Direito brasileiro. ${ }^{63}$ É evidente que o racismo, como mecanismo de opressão, se estratifica e se aclimata a diferentes lugares, momentos e populações. O racismo sofrido por asiáticos, por exemplo, não se confunde com o sofrido por latinos. ${ }^{64}$ Melhor seria, pois, que falássemos em racismos, no plural. Alguns intelectuais vinculados à CRT recorrem à noção de 'racialização diferencial', para pensar tais "adaptações". ${ }^{65}$ Não devemos "importar" acriticamente, na análise do racismo pátrio, conceitos cunhados alhures. Todavia, o diálogo com a CRT ajuda a descortinar práticas que, em nosso contexto - ainda muito marcado pelo "mito da democracia racial" -, restariam, de outro modo, obnubiladas. Como uma ferramenta para desvelar as microagressões ${ }^{66}$ que, nos palácios de governo, nas assembleias, nos fóruns e nas ruas, escondem-se por trás da máscara da "neutralidade" e da "cegueira da cor", a CRT segue sendo, depois de quatro décadas, atualíssima. Nosso desafio, enquanto juristas do século XXI nascidos do lado de baixo do Equador, é traduzir - ou melhor: transcriar, para valermo-nos do termo do crítico literário Haroldo de Campos - o impulso orientador da CRT, para além das especificidades da cultura estadunidense. Para explorarmos o rico potencial heurístico e revolucionário da CRT na educação jurídica, devemos ser fiéis ao seu espírito - traindo, se preciso, a sua letra.

\section{A TEORIA RACIAL CRÍTICA ASIÁTICA E O “VÍRUS CHINÊS”}

Desde que a pandemia de coronavírus começou, inúmeros episódios de agressão a descendentes de asiáticos foram relatados. ${ }^{67}$ Chineses - e indivíduos tomados por chineses -

\footnotetext{
${ }^{63}$ Precisamos racializar - "aquilombar" - o ensino jurídico, que continua sendo marcadamente eurocentrado. A universidade brasileira, de forma geral (e as faculdades de Direito, em particular), apresenta uma proporção irrisória de professores pretos e pardos, o que se reflete no conteúdo pautado em classe: "Assim, apesar dos avanços contemporâneos e da expansão do ensino universitário na última década, a presença negra na docência permanece diminuta. Como desencadeador dessa realidade, atua o passivo histórico de um projeto social exclusivista que, desde o limiar da República, orienta a nação e tem na educação um dos seus instrumentos base: a escola pública tornou-se um espaço branco, porque branca era a cor da civilização e da modernidade".ARBOLEYA, Arilda et. al. "Educação para uma vida melhor": trajetórias sociais de docentes negros. Cadernos de Pesquisa, v. 45, n. 158, p. 883 a 914, outubro a dezembro de 2015, p. 889. Disponível em: https://www.scielo.br/pdf/cp/v45n158/1980-5314-cp-45-158-00882.pdf. Acessado em: 29 de abril de 2020.

${ }^{64}$ Sobre o tema, v. CHANG, Robert S.; GOTANDA, Neil. The Race Question in LatCrit Theory and Asian American Jurisprudence. Nevada law Journal, v. 7, p. 1012 a 1029, verão de 2007.

${ }^{65} \mathrm{~V}$. HUTCHINSON, Darren Leonard. "Out Yet Unseen": a racial critique of gay and lesbian legal theory and political discourse. Connectcut Law Rivew, n. 28, v. 2, p. 561 a 645, 1997.

${ }^{66}$ Sobre o conceito de 'microagressão', recomendamos a leitura de DAVIS, Peggy Cooper. Law as microagression. The Yale Law Journal, v. 98, p. 1559-1577, June 1989.

${ }^{67} \mathrm{Cf}$. CUMMINS, Eleanor. The new coronavirus is not an excuse to be racist. The Verge, New York, 4 de fevereiro de 2020. Disponível em: https://www.theverge.com/2020/2/4/21121358/coronavirus-racism-social-mediaeast-asian-chinese-xenophobia. Acessado em: 22 de maio de 2021.
} 
foram atacados ao argumento de que estariam propagando a doença. Ainda hoje, é difundida a crença de o vírus seria uma arma biológica do governo chinês. Referindo-se ao COVID-19 como "vírus de Wuhan" ou "vírus estrangeiro", muitos políticos ocidentais contribuíram para popularizar essa tese. Exploraram a pandemia como um artifício para recrudescer os apelos xenofóbicos da Nova Direita: expulsão de imigrantes, fechamento de fronteiras, desmantelamento de organizações internacionais e transnacionais etc. ${ }^{68}$ Pessoas amarelas passaram a ser retratadas, assim, como "comedores de morcegos". Campanhas contra semelhante caracterização midiática - como \#JeNeSuisPasUnVirus - foram deflagradas, em um esforço para conter essa violência racializada. ${ }^{69}$

Essa associação entre raça e doença não é nova. O grande intelectual W. E. B. Du Bois já alertava para a forma como o governo norte-americano, entre o fim do século XIX e o início do século $X X$, passara a representar negros e irlandeses como disseminadores de tuberculose. ${ }^{70}$ Epidemias de varíola, no Canadá do século XIX, foram erroneamente atribuídas aos chineses, o que levou, em 1886, a manifestações anti-asiáticas em Vancouver. ${ }^{71} \mathrm{Um}$ dos pilares do mito do "perigo amarelo" foi a crença de que asiáticos seriam propagadores de doenças como sífilis, lepra e varíola. Essa fantasia foi evocada, reiteradas vezes, para sustentar normas anti-imigratórias, como, nos EUA, a Chinese Exclusion Act, de 1882, e, no Brasil, o Decreto 528, de 28 de junho de 1890. Doutrinas racistas, com frequência, referem-se ao grupo racial dominante como um corpo, que precisa ser protegido contra a contaminação que os imigrantes (grupos raciais subordinados) representam. ${ }^{72}$ Para além de uma metáfora (pobre), essa identificação do Outro como um fator de contágio reverberou (e ainda reverbera!) em políticas de saúde e de segurança (higienismo social). Razão pela qual a "cegueira racial da assistência médica" (color-blind helth care), quer dizer, a tentativa de pensar os projetos de saúde pública ignorando o papel estruturante do racismo, não permite que façamos uma análise realista do "apartheid sanitário" que impera no Ocidente. Nessa conjuntura, a Teoria Racial Crítica pode oferecer aportes importantes.

Nas últimas décadas, a CRT ramificou-se em diversas vertentes: a QueerCrit (Teoria Racial Crítica Queer), a DisCrit (Dis/ability Critical Race Theory, quer dizer, Teoria Racial Crítica da D/eficiência), a LatCrit (Teoria Racial Crítica Latina), a TribalCrit (Teoria Racial Crítica Nativoamericana) etc. Sob influência das reflexões de Kimberlé Crenshaw acerca da categoria de

\footnotetext{
${ }^{68}$ Cf. BURUMA, lan. Virus as Metaphor. The New York Times, New York, 28 de março de 2020. Disponível em: https://www.nytimes.com/2020/03/28/opinion/coronavirus-racism-covid.html. Acessado em: 19 de maio de 2021.

${ }^{69}$ V. RIBEIRO, Alexandre. Racismo velado e o coronavírus na Alemanha. ItaúCultural, São Paulo, 11 de maio de 2020. Disponível em: https://www.itaucultural.org.br/secoes/colunistas/racismo-velado-e-o-coronavirus-naalemanha. Acessado em: 21 de maio de 2021.

${ }^{70}$ Cf. BAILEY, Zinzi et al. Racism in the time of COVID-19, IAPHS: Interdisciplinary Association for Population Health Science, Eagle, 9 de abril de 2020. Disponível em: https://iaphs.org/racism-in-the-time-of-covid-19/. Acessado em: 22 de maio de 2021.

${ }^{71}$ Cf. LARSON, Paula. Anti-Asian racism during coronavirus: how the language of disease produces hate and violence. The Conversation, Waltham, 31 de março de 2020. Disponível em: https://theconversation.com/antiasian-racism-during-coronavirus-how-the-language-of-disease-produces-hate-and-violence-134496. Acessado em: 22 de maio de 2020.

${ }^{72} \mathrm{Na}$ lição de Karen Shimakawa: "The Chinaman was and remains a fantastic figment of the American and Western imagination. Serving multiple purposes in multiple places and multiple moments. So conjured, he is also symbolically and ritually tortured. Add up all these visual stigmas and a visual common sense of non-normative, queer disgust is formulated, serialized, and looped". SHIMAKAWA, Karen. National Abjetion. In: TCHEN, John Kuo Wei; YEATS, Dylan (Org.). Yellow Peril!: an archive of anti-asian fear. London; New York: 2014, p. 344.
} 
'interseccionalidade', ${ }^{73}$ essas correntes se propõem a investigar a forma como o racismo amolda-se a diferentes grupos vulneráveis. Se, como reza um dos principais slogans da CRT, "raça importa!", raças diferentes irão, na percepção de intelectuais relacionados à LatCrit, à TribalCrit etc., importar diferentemente. Rompendo com o binarismo branco/preto e com a pigmentocracia ${ }^{74}$, figuras como Kin Chanbonpin trabalharão para tornar visíveis as formas de discriminação e de segregação sofridas por latinos, asiáticos, nativos etc. (que não se confundem, necessariamente, com os mecanismos de opressão operacionalizados contra afrodescendentes). ${ }^{75} \mathrm{Se}$ as doutrinas jurídicas hegemônicas pecam por fazer do olhar do homem branco heterossexual cisgênero de classe média sem deficiência o "grau zero do conhecimento" (representando seus valores e crenças como "lugares comuns", neutros, pontos incontroversos...), a CRT buscou evitar a "essencialização" da perspectiva do homem negro heterossexual cisgênero de classe média sem deficiência - encampando uma abordagem radicalmente plural e polifônica, atenta às especificidades dos inúmeros grupos raciais subordinados. ${ }^{76}$ Como pontifica Robert S. Chang:

\begin{abstract}
Podem ser traçadas analogias entre a discriminação experimentada por diferentes grupos sem poder, mas deve-se tomar cuidado para evitar confundir uma forma de discriminação com outra. O grupo dominante usou vários métodos de discriminação, legais e extralegais, contra diferentes grupos sem poder. As diferenças entre esses grupos devem ser consideradas em um discurso sobre raça e Direito, se quisermos usar o Direito como meio de ajudar a acabar com a opressão racial. ${ }^{77}$
\end{abstract}

\footnotetext{
${ }^{73}$ CRENSHAW, Kimberlé. Mapping the Margins: Intersectionality, Identity Politics, and Violence Against Women of Color, Stanford Law Review, v. 43, n. 6, p. 1241 a 1299, 1991.

74 Pigmentocracia é colorismo, e se traduz, por exemplo, na ideia de que latinos, asiáticos etc. seriam "intermediários" entre dois polos, os brancos e os pretos. Trata-se de uma lógica que incide, também, sobre asiático-americanos - é possível observar comunidades que preterem pessoas de pele mais escura, entre descendentes de filipinos, indianos, vietnamitas e japoneses que vivem no Ocidente. Nas palavras de Kin Chanbonpin: "Darker-skinned Asian groups are widely considered to be the bottom of the Asian American social hierarchy". CHANBONPIN, Kin D. Between Black and White: The Coloring of Asian Americans. Washington University Global Studies Law Review, v. 14, p. 637 a 663, 2015, p. 644. Disponível em: https://repository.jmls.edu/cgi/viewcontent.cgi?article=1624\&context=facpubs. Acessado em: 7 de julho de 2020.

${ }^{75}$ Sobre o paradigma branco/preto, Kin Chanbonpin: "The prevailing paradigm for understanding and discussing race relations in the United States is the Black/White binary. Although many have embraced the binary as a valuable tool for framing contemporary discussons about race relations, several legal scholars have decried the dichromatic model as inaccurately representing the nation's numerous and varied racial and ethnic groups". CHANBONPIN. Between Black and White..., p. 641.

${ }^{76}$ A propósito, o célebre Neil Gotanda observa: "In the existing literature of racial studies outside the "blackwhite paradigm', there is often an unstated assumption that race will carry the same meaning for all non white races, even across different legal and social settings. However, in my own work on Asian Americans and race, I have rejected the automatic assumption that the racialization of whites, blacks, and Asians are identical. Rather, I have examined how the process of differentiating whites from Chinese, Japanese, and other Asians is both similar to and different from white-black racialization". GOTANDA, Neil. The "common sense" of race. Southern California Law Review, Los Angeles, v. 83, p. 441 a 452, 2010, p. 446.

77 Tradução nossa para: "Analogies may be drawn between the discrimination experienced by different disempowered groups, but care must be taken to avoid confusing one form of discrimination with another. The dominant group has used various methods of discrimination, legal and extralegal, against different disempowered groups. The differences between these groups must be considered in a discourse on race and the law if we are to use law as means to help end racial oppression". CHANG, Robert S. Toward an Asian American Legal Scholarship: Critical Race Theory, Post-structuralism, and Narrative Space. California Law Review, Los
} 
Identidades raciais não são naturais, autoevidentes, óbvias e inquestionáveis - são construções sócio-históricas, que dependem de tensões e negociações de natureza política e econômica. Daí que comunidades possam, no correr do tempo, ser racializadas ou des-racializadas, com base nas pretensões e nas expectativas da cultura hegemônica (é o caso dos imigrantes irlandeses na América do Norte, nos séculos XIX e XX). Raça é categoria instável, e a linha da cor desloca-se ao sabor dos ventos e das conveniências. Nas palavras de Chanbonpin: "Raça não é uma característica fixa de identidade, mas sim socialmente construída e mutável. As categorias raciais e os significados a elas atribuídos podem, portanto, ser interrogados com referência às contingências do tempo e do espaço". ${ }^{78}$ Como já indicaram alguns juristas vinculados à CRT: "raça é performance!". ${ }^{79}$

É nessa paisagem que emerge a AsianCrit (Teoria Racial Crítica Asiática). Contra o mito da "minoria modelo", segundo o qual descendentes de asiáticos no Ocidente seriam "brancos honorários", plenamente integrados (e símbolos, por conseguinte, das virtudes do capitalismo meritocrático), a AsianCrit mostrará como a maioria das pessoas amarelas nascidas nos EUA seguem sendo estrangeiros perpétuos em seu próprio país, inassimiláveis à sociedade branca. ${ }^{80}$ Sua lealdade aos EUA é reiteradamente questionada, o que os condena a viver em enclaves étnicos, guetos, chinatowns. Muitos se submetem a cirurgias de des-etnicização, em uma tentativa de serem socialmente "lidos" como brancos. Assim, longe de serem - como a mídia norte-americana, desde o célebre artigo Success Story, Japanese-American Style, publicado em 1966 na New York Times Magazine por William Petersen, procura disseminar - um emblema do potencial inclusivo do liberalismo, asiático-americanos possuem trajetórias marcadas pelo preconceito e pela marginalização. ${ }^{81}$ Essa permanente "estrangeiridade", que se inscreve nos corpos dos "orientais" no Ocidente, será o ponto de partida das pesquisas desenvolvidas pela AsianCrit - vale lembrar que, até há poucas décadas, vigiam, em vários países

\footnotetext{
Angeles, v. 81, p. 1241 a 1323, 1993, p. 1265. Disponível em: https://digitalcommons.law.seattleu.edu/cgi/viewcontent.cgi?article=1411\&context=faculty. Acessado em: 8 de julho de 2020.

78 Tradução nossa para: "Race is not a fixed identity characteristic, but is, rather, socially constructed and mutable. Racial categories and the meanings ascribed to them can therefore be interrogated with reference to the contingencies of time and space". CHANBONPIN. Between Black and White..., p. 652.

${ }^{79}$ V. LÓPEZ, Ian F. Haney. The Social Construction of Race. DELGADO, Richard (Org.). Critical Race Theory: The Cutting Edge. Philadelphia: Temple University Press, 1995.

${ }^{80}$ Conforme Robert S. Chang: "That Asian Americans are a "model minority" is a myth. But the myth has gained a substantial following, both inside and outside the Asian American community. The successful inculcation of the model minority myth has created an audience unsympathetic to the problems of Asian Americans. Thus, when we try to make our problems known, our complaints of discrimination or calls for remedial action are seen as unwarranted and inappropriate. They can even spark resentment". CHANG. Toward an Asian American Legal Scholarship..., cit., p. 1260.

${ }^{81}$ Nas palavras de Chanbonpin: "The Model Minority Myth was designed to mollify the societal tensions brought to the fore by these burgeoning social movements. The success of Asian Americans was intended to serve as proof that racism was not to blame for failure to achieve the American Dream. Rather, the Myth promoted the notion that poor conditions in Black communities were the result of Black cultural inadequacies. Positioned as a wedge in a social system that subordinates Black people, many - thought not all - Asian American groups thrived". CHANBONPIN. Between Black and White..., p. 652. Cf., também, KOLANO, Lan. Smartness as cultural wealth: an AsianCrit counterstory. Race Ethnicity and Education, London, v. 19, n. 6, p. 1149 a 1163, 2016. Disponível em: https://www.libs.uga.edu/reserves/docs/main-spring2018/freemanqual8400/kolano_smartness\%20as\%20cultural\%20wealth.pdf. Acessado em: 7 de julho de 2020.
} 
do Ocidente, normas que proibiam a naturalização de amarelos. A formação de uma identidade genuinamente asiático-americana, intensificada por experiências compartilhadas de discriminação, permite que pessoas amarelas comecem a postular, dentro da Teoria Racial Crítica, temas, problemas e métodos próprios. ${ }^{82}$

As estratégias de mobilização antirracista elaboradas a partir dos pleitos dos negros norte-americanos não contemplam, necessariamente, outras "minorias" étnicas. É dessa percepção que nasce a AsianCrit. Por séculos, afroamericanos concentraram suas pautas sociais em torno de reivindicações por direitos individuais, civis e políticos. Mas, no caso de culturas - como as indígenas e as asiáticas - nas quais o comunitário impõe-se sobre o individual, conquistas de liberdades e garantias subjetivas podem não ser suficientes. Valores como a "tradição" e a "ancestralidade" não são devidamente tutelados por declarações de direitos, aos moldes das revoluções liberais. Na lição de Chang:

\begin{abstract}
Em primeiro lugar, a luta tradicional por direitos civis, com sua base na filosofia política liberal, é calcada em concepções de direitos individuais. Esses direitos têm como premissa a noção de um eu autônomo individualizado. No entanto, esse eu autônomo individualizado pode não refletir a realidade de todos os asiático-americanos e das culturas das quais eles derivam. Muitas filosofias e culturas asiáticas têm em seu centro o conceito de não-eu. E ao menos um idioma asiático não tem uma palavra para 'eu' que corresponda a 'eu' em inglês. Assim, para alguns asiático-americanos, a luta tradicional por direitos civis pode estar em desacordo com sua autoconcepção e visão de mundo. ${ }^{83}$
\end{abstract}

Daí que, diversamente do que poderíamos pensar, a superação do liberalismo jurídico moderno possa representar, para os asiático-americanos, um desafio mais urgente que para outros grupos raciais subalternizados. E, como sugere Neil Gotanda, essa constatação confere, à AsianCrit, um perfil mais radical que muitas outras ramificações da CRT. ${ }^{84} \mathrm{O}$ imaginário ocidental, com frequência, retrata asiáticos como "quietos", "diligentes", "conformados com o status quo" - características vistas como virtudes, que assegurariam a eles o "ingresso" em posições de poder nas Américas e na Europa. Seriam, dessa maneira, um exemplo de que a "cegueira da cor" funciona, e de que demandas por justiça racial constituem-se em reivindicações de "privilégios". Porém, ligeiras flutuações nas relações de poder, em contexto geoes-

\footnotetext{
82 V. CHANG, Robert S. The Invention of Asian Americans. UC Irvine Law Review, Irvine, v. 3, p. 947 a 964, 2013. V., ainda, GOTANDA, Neil. Inventing Asian American. University of California, Davis, Los Angeles, v. 45, p. 1885 a 1888, 2012. Disponível em: https://lawreview.law.ucdavis.edu/issues/45/5/Articles/45-5_Gotanda.pdf. Acessado em: 07 de julho de 2020.

${ }^{83}$ Tradução nossa para: "First, tradicional civil rights work, with its foundation in liberal political philosophy, is based upon conceptions of individual rights. These rights are premised on the notion of an individuated autonomous self. However, this individuated autonomous self may not reflect the reality of all Asian Americans and the cultures from which they come. Many Asian philosophies and cultures have at their center the concept of no-self. And at least one Asian language does not have a word for ' $I$ ' that corresponds to ' $I$ ' in English. Thus, for some Asian Americans, tradicional civil rights work may be at odds with their self-conception and worldview". CHANG. Toward an Asian American Legal Scholarship..., cit., p. 1265 e 1266.

${ }^{84} \mathrm{~V}$. GOTANDA, Neil. Critical Legal Studies, Critical Race Theory and Asian American Studies. Amerasia Journal, v. 21, n. 1-2, p. 127 a 136, 1995.
} 
tratégico (disputas comerciais entre os EUA e a China, por exemplo) bastam para que os amarelos sejam racializados, sujeitos a perseguições e violências oficiais e extraoficiais. ${ }^{85}$ Vê-se, pois, que o mito da minoria modelo beneficia, apenas, a supremacia branca. ${ }^{86}$ Desde a Antiguidade, "orientais" são, sistematicamente, associados por nosso imaginário a despotismo, corrupção, decadência moral, vulgaridade, vaidade e esplendor luxuoso. Essas caricaturas que, em meio às lutas anticoloniais, serão condensadas na figura ficcional do Dr. Fu Manchu ${ }^{87}$ - são, ainda hoje, reavivadas, sempre que os interesses de nações ocidentais colidem com pretensões de povos asiáticos. A ideia de "perigo amarelo" orbita em torno desses tropoi. Um exemplo: como forma de refrear a imigração de asiáticos para a América do Norte ("invasão insidiosa", para muitos brancos estadunidenses), jornais da década de 1960 publicavam gravuras que representavam chineses canibalizando - juntamente com irlandeses - o Tio Sam.

Essas considerações ajudam a compreender o motivo de muitos governos terem se valido da pandemia para disseminar o ódio contra amarelos, apoiando teorias conspiratórias etc. Como a Teoria Racial Crítica demonstra, a divisão internacional do trabalho estrutura-se em termos raciais, e a manutenção dos privilégios de brancos, no Ocidente, pressupõe um trabalho contínuo de "demonização" de outros grupos étnicos. Nesse sentido, o coronavírus passa a ser visto, não como uma tragédia, mas como uma oportunidade - de acelerar processos de segregação, de precarização e de suspensão de direitos, ao argumento de que tais medidas seriam necessárias no enfrentamento da crise. A lógica do "capitalismo do desastre", bem apontada pela jornalista Naomi Klein em trabalhos recentes, também é racista, e ressuscita antigas fantasias - como o do "perigo amarelo" - como ferramenta para legitimar embates políticos e econômicos. Nessa conjuntura, as considerações da AsianCrit acerca da construção social da raça amarela - e o esforço, correlato, para desmistificar a ideia de "minoria modelo" - oferecem aportes importantes.

\footnotetext{
${ }^{85}$ V. MUSEUS, S. D.; IFIKAR, Jon. An Asian Critical Theory (AsianCrit) Framework: Asian students in higher education. New York: Routledge, 2013.

${ }^{86}$ Conforme Sohyun An: "In school students rarely learn about the Asian American experience in the study of U.S. history. Asian Americans and their long struggle for equity are almost invisible in school curricula, which, according to Asian critical race theory, contribute to the resiliency of white supremacy. Since American national identity is defined by whiteness, Asian Americans are regarded as illegitimate Americans, and the exclusion of Asian Americans from U.S. history curricula is warranted. Consequently, the curricular exclusion sends explicit and implicit messages to students that being American means being white and that Asian Americans are not real Americans". AN, Sohyun. AsianCrit as a Theoretical Lens to Trouble and Transform White Supremacy. In: HAWKMAN, Andrea M.; SHEAR, Sarah B. (Org.). Marking the "Invisible": Articulating Whiteness in Social Studies Education. Charlotte: Information Age Publishing, 2020, p. 5 e 6.

${ }^{87}$ Acerca do Dr. Fu Manchu, John Tchen observa: "Instead, the inscrutable Dr. Fu Manchu uses his Western intellect and Eastern cunning to try to destroy Western Civilization and beat it at its own game of world conquest. He organizes the colonized against the British, and picks off colonial administrators who catch on to his plot. This sublimated revenge fantasy helps make sense.of why the Devil Doctor seems to take so much pleasure in his ability to outwit and terrify the British. The messy details of Western violence need not complicate the story of Western purity and innocence. In a paranoid political culture, seemingly random disruptions of London's peace can be explained simply and elegantly: The East wants to annihilate the West". TCHEN; YEATS. Introdution: Yellow Peril Incarnate. In: TCHEN; YEATS (Org.). Yellow Peril!..., cit., p. 5.
} 


\section{CONCLUSÃO: UM PASSO ALÉM DE SONTAG}

Ainda está por ser redigida uma história da doença como metáfora racial. Grupos nãobrancos específicos são associados a doenças determinadas; doenças específicas são associadas a grupos não-brancos determinados. As identidades raciais, como constructos socioculturais que se transformam no correr do tempo, lançam pré-concepções e pré-juízos a respeito do corpo do outro, chaves a partir dos quais o corpo do outro será "lido". Se, como Susan Sontag já observou, o imaginário relativo a doenças é utilizado como um instrumento de segregação de comunidades não-hegemônicas, então, em uma sociedade racializada, a mitologia em torno de vírus e bactérias será manuseada com o fito de conservar e validar sistemas de exclusão. Seria possível mapear quais doenças foram, no curso dos anos, associados a quais grupos raciais subalternizados - e qual arquitetura jurídico-política subsidiou tais associações. A Teoria Racial Crítica pode, aqui, servir-nos de auxílio, para que demos um passo além de Sontag, e entendamos como a "linha da cor" impacta na elaboração de representações sociais acerca de doenças. A pandemia de coronavírus constitui-se em um caso emblemático. Por um lado, é possível perceber (aplicando noções da CRT) como o COVID-19 impacta diferentemente grupos raciais diversos - e como medidas de saúde pública que não levam o racismo estrutural em consideração, por se pressuporem "neutras", acabam acelerando a morte de comunidades não-brancas. ${ }^{88}$ Por outro lado, não é difícil constatar (ancorados na AsianCrit) que o resgate do mito do "perigo amarelo" foi importante para que governos de extrema direita se aproveitassem da pandemia para fortalecer projetos xenofóbicos e ampliar estratégias de flexibilização de direitos. Em uma civilização racista e neocolonial, precisamos atentar para a forma como a "linha da cor" estrutura as relações sociais - e isso inclui a maneira como nos relacionamos com o corpo, o nosso e o alheio. A pandemia explicita a forma como as desigualdades promovidas pelo racismo perpassam nossa vida cotidiana, por vezes de forma velada, silente, mas inescapável.

\section{REFERÊNCIAS}

BELL, Derrick. Brown v. Board of Education and the Interest Convergence Dilemma. Harvard Law Review, v. 93, n. 1, Cambridge, p. 518 a 533, janeiro de 1980.

CHANG, Robert S. The Invention of Asian Americans. UC Irvine Law Review, Irvine, v. 3, p. 947 a 964, 2013. V., ainda, GOTANDA, Neil. Inventing Asian American. University of California, Davis, Los Angeles, v. 45, p. 1885 a 1888, 2012. Disponível em: https://lawreview.law.ucdavis.edu/issues/45/5/Articles/45-5_Gotanda.pdf. Acessado em: 07 de julho de 2020.

CHOMILO, Nathan T. et al. The harm of a colorblind allocation of scarce resources. Health Affairs, Bethesda, 20 de abril de 2020. Disponivel em: https://www.healthaffairs.org/do/10.1377/hblog20200428.904804/full/. Acessado em: 21 de maio de 2021.

\footnotetext{
${ }^{88}$ Sobre o tema, recomendamos a leitura de CALDWELL, Kia Lilly. Health Equity in Brazil: Intersections of Gender, Race, and Policy. Champaign: University of Illinois Press, 2017.
} 
CRENSHAW, Kimberlé. Mapping the Margins: Intersectionality, Identity Politics, and Violence Against Women of Color, Stanford Law Review, v. 43, n. 6, p. 1241 a 1299, 1991.

DIAMOND, Jared. Armas, germes e aço: os destinos das sociedades humanas. Tradução de Silvia de Souza Costa, Cynthia Cortes e Paulo Soares. Rio de Janeiro: Record, 1997.

GOTANDA, Neil. Critical Legal Studies, Critical Race Theory and Asian American Studies. Amerasia Journal, v. 21, n. 1-2, p. 127 a 136, 1995.

HARRIS, Angela P. Compassion and Critique. Columbia Journal of Race and Law, New York, v. 1, n. 3, p. p. 326 a 352, 2012.

HUTCHINSON, Darren Leonard. "Out Yet Unseen": a racial critique of gay and lesbian legal theory and political discourse. Connectcut Law Rivew, n. 28, v. 2, p. 561 a 645, 1997.

MBEMBE, Achille. Direito universal à respiração. Tradução de Ana L. Braga. São Paulo: $\mathrm{n}-1$ edições [no 20], 2020. Disponível em: https://n-1edicoes.org/020. Acessado em: 21 de maio de 2021.

MUSEUS, S. D.; IFIKAR, Jon. An Asian Critical Theory (AsianCrit) Framework: Asian students in higher education. New York: Routledge, 2013.

PINHEIRO-MACHADO, Rosana. Coronavírus não é democrático: pobres, precarizados e mulheres vão sofrer mais. The Intercept Brasil, 17 de março de 2020. Disponível em: https://theintercept.com/2020/03/17/coronavirus-pandemia-opressao-social/. Acessado em: 14 de agosto de 2020.

RIBEIRO, Alexandre. Racismo velado e o coronavírus na Alemanha. ItaúCultural, São Paulo, 11 de maio de 2020. Disponível em: https://www.itaucultural.org.br/secoes/colunistas/racismovelado-e-o-coronavirus-na-alemanha. Acessado em: 21 de maio de 2021. 